www.jmscr.igmpublication.org

Index Copernicus Value: 79.54

ISSN (e)-2347-176x ISSN (p) 2455-0450

crossref DOI: https://dx.doi.org/10.18535/jmscr/v7i4.147

\title{
Anaplastic type of primary cardiac lymphoma- a rare presentation of left atrial mass
}

\author{
Authors \\ Vijay Shewale ${ }^{1}$, Chaitanya Raut ${ }^{2 *}$, Prashant Mishra ${ }^{3}$, Jayant Khandekar ${ }^{4}$ \\ ${ }^{1}$ MBBS DNB, Resident Doctor, Dept of CVTS, LTMMC\& GH, Sion, Mumbai \\ ${ }^{2}$ MBBS MS MCH DNB, Asst Prof, Dept of CVTS, LTMMC\& GH, Sion, Mumbai \\ ${ }^{3,4}$ MBBS MS MCH, Prof, Dept of CVTS, LTMMC\& GH, Sion, Mumbai \\ *Corresponding Author \\ Chaitanya Raut \\ Email: drrautchaitanya@gmail.com
}

\begin{abstract}
Primary cardiac tumor are rare with incidence of $0.056 \%$ in autopsy reports. Approximately $90 \%$ of primary cardiac tumors are benign, the most common is myxoma, other types, including rhabdomyoma, lipoma, papillary fibroelastoma, fibroma, hemangioma, teratoma, sarcoma. The remaining $10 \%$ are malignant, out of which $95 \%$ are sarcomas and 5\% of are lymphomas and mesotheliomas. Here, we reported rare case of primary cardiac lymphoma with a very rare subtype that is high grade Anaplastic large cell lymphoma (ALCL) in 20 years old female who presented with acute pulmonary edema and underwent emergency surgery for left atrial mass excision.
\end{abstract}

\section{Introduction}

Primary cardiac lymphoma (PCL) is defined as extranodal lymphoma involving only the heart and /or pericardium or lymphoma presenting with cardiac manifestations particularly if bulk of disease was found in heart or pericardium. ${ }^{[1]} \mathrm{PCL}$ constitutes about 1.3-2 \% of all cardiac tumors, $5 \%$ of all primary malignant tumor of heart and $0.5 \%$ of all extranodal lymphomas. Secondary cardiac involvement in disseminated and terminal stage of non Hodgkin lymphoma is $9-24 \%$.The most common histological type of PCL is diffuse B cell lymphoma. ${ }^{[2]}$ Here, we reported rare case of PCL which is high grade Anaplastic large cell lymphoma (ALCL).

\section{Case Report}

20 years old female presented with acute pulmonary edema in emergency room in april 2018. Patient gave history dyspnoea on exertion class III for 1 month, which is increased to class IV for 2 days. No history of chest pain, palpitations or syncope. On examination heart rate $100 /$ minute, blood pressure $90 / 60 \mathrm{~mm}$ of $\mathrm{hg}$, respiratory rate 35/minute, saturation- $90 \%$. In view of persistent tachypnoea and desaturation, patient was intubated and ventilated. Urgent $2 \mathrm{D}$ ECHO done which showed, large mass (46X43 $\mathrm{mm}$ ) noted in left atrium (LA) obstructing mitral valve with minimal blood flow across mitral valve, severe tricuspid regurgitation, severe pulmonary hypertension (pulmonary artery 


\section{JMSCR Vol||07||Issue||04||Page 884-886||April}

systolic pressure $84 \mathrm{~mm}$ of hg) and dilated right atrium, right ventricle (TAPSE -11). Patient was immediately taken for left atrial mass excision. Aorto - bicaval cannulation done and patient was put on cardiopulmonary bypass (CPB) .Cold cardioplegia delivered and heart arrested in diastole. Left atrium opened through right atrium and transeptal route. Findings (Figure 1) - large lobulated hard mass occupying whole of LA with dense adhesions. Part of mass extending across mitral valve in left ventricle. Whole mass excised preserving mitral valve, patient weaned off CPB and shifted to recovery room. On post op day 2 , patient developed severe mitral regurgitation and underwent mitral valve replacement. Patient expired on post op day 3 because of persistent cardiogenic shock.

Histopathology (HP) report (Figure-2) gross specimen- yellow white tissue mass measuring 4 X $3 \times 3 \mathrm{~cm}$ size, firm to hard in consistency, lobulated appearance. Microscopy (Figure-3) showed high grade hematolymphoid malignancy, large area of necrosis seen. Immunohistochemistry (IHC) showed tumor cells positive for LCA, CD30, CD43 and weakly positive for CD4 and ALK-1. They are negative for MIC-2, FLI-1, Desmin, Myogenin, WT-1, Calponin, MPO, Tdt, CD34, C-kit, CD138, CD20, PAX5 and CD79a. $\mathrm{HP}$ and IHC suggestive of high grade ALK positive anaplastic large cell lymphoma (ALCL).

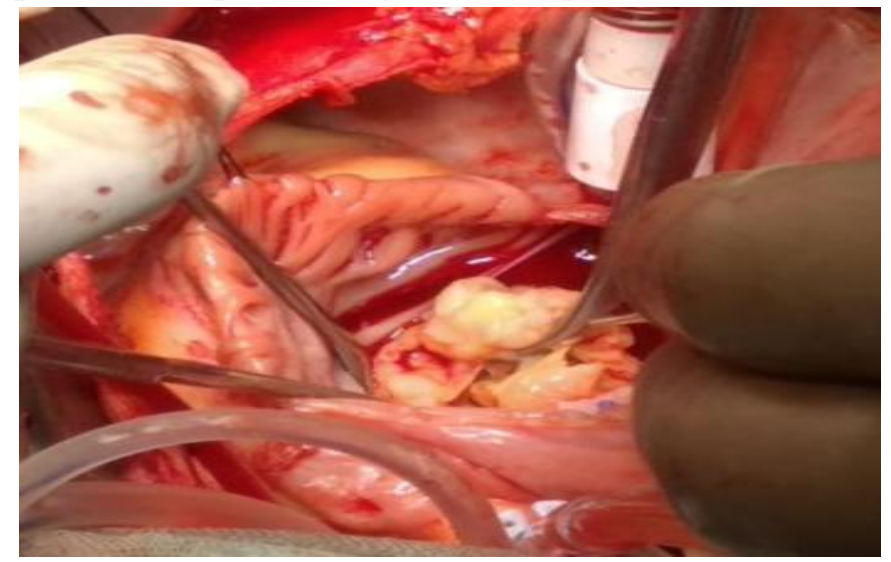

Figure 1 Through right atrium, inter atrial septum excised at fossa ovalis, large lobulated hard mass seen occupying whole of LA with dense adhesions. Part of mass extending across mitral valve in left ventricle.

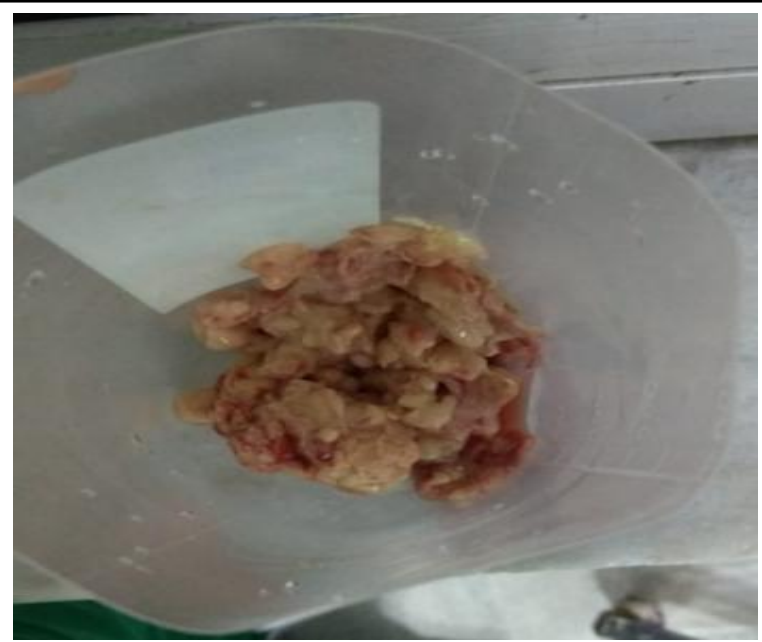

Figure 2 - Gross specimen - Left atrial mass of $4 \times 3 \times 3 \mathrm{~cm}$ size, firm to hard consistency.

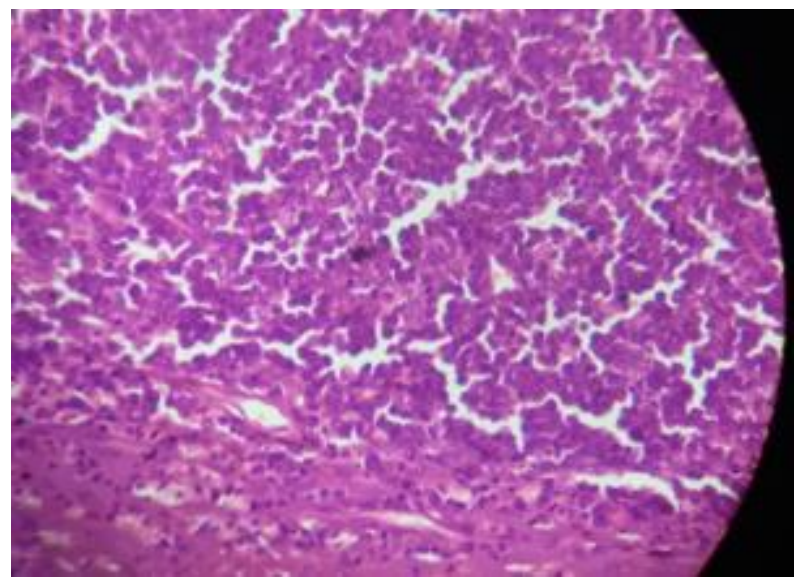

Figure 3- Histopathology examination showed high grade hematolymphoid malignancy, large area of necrosis seen.

\section{Comment}

PCL is a rare disease. The largest review of casereports was performed by Petrich et al. The series included 197 cases of PCL reports from 1947 2009. The authors reported that this disease is more common in the elderly age. The median age of the patients is 63 years, although it ranged from 9 to 90 years (but only 5 patients were younger than 17 years old). The reported male to female ratio was $2: 1 .^{[1]}$

The major clinical presentation of PCL include dyspnoea, heart failure, chest pain, life threatening arrhythmia due to tumor invasion of the conduction system or irritation of myocardium, pleural effusion, pericardial effusion and shock due to cardiac tamponade or obstruction of blood 
flow. Constitutional symptoms, including fever, chills, sweats and weight loss, are also common. In some PCL cases, patients may develop pulmonary or cerebral embolism. ${ }^{[3]}$

In $92 \%$ of PCL cases reported, the right heart chambers were involved, predominantly the right atrium. By contrast, in only $7 \%$ of cases, the left heart was involved without right heart invasion. In $25 \%$ of PCL cases, the superior vena cava was also affected. Diffuse large B-cell lymphoma is the most common sub-type of PCL (113 cases reported); the remaining sub-types include Burkitt's lymphoma, T-cell lymphoma, small lymphocytic lymphoma and plasmablastic lymphoma. ${ }^{[1]}$

Treatment approaches include combinations of: chemotherapy, radiotherapy, tumor mass resection, and autologous stem cell transplant. Chemotherapy is the most effective treatment of $\mathrm{PCL}^{[4]}$. Chin et al. reported that when treating with chemotherapy alone $61 \%$ of patients have a remission, while surgery alone has no effect to the outcome, because it is difficult to resect the tumor completely ${ }^{[5]}$. Anthracycline containing regimens, primarily CHOP plus rituximab have been commonly performed and with good response ${ }^{[6]}$. Risks of chemotherapy include cardiac rupture when rapid tumor regression occurs, massive pulmonary emboli, refractory heart failure, or cardiac arrhythmia.

The prognosis of PCL is so poor that most patients die within a few weeks following the diagnosis. Survival is mainly affected by 4 factors: immune status, left ventricular involvement, presence of extra-cardiac disease, and arrhythmia ${ }^{[1]}$. The longest survival was reported by Groton et al for a patient treated with surgical resection and adjuvant chemotherapy survived for more than 13 years $^{[7]}$. Almost all of the literature are case reports, which makes the analysis of outcome very difficult.

Primary cardiac lymphoma is an extremely rare condition with various non-specific symptoms, but a high mortality rate. A prompt and proper diagnosis may affect the prognosis. However, their biological and clinical characteristics are still unknown and more cases should be discussed.

\section{References}

1. Petrich A, Cho SI and Billett H: Primary cardiac lymphoma: An analysis of presentation, treatment and outcome patterns. Cancer 117: 581-589, 2011.

2. Ceresoli GL, Ferreri AJ, Bucci E, Ripa C, Ponzoni $\mathrm{M}$ and Villa E: Primary cardiac lymphoma in immunocompetent patients: Diagnostic and therapeutic management. Cancer 80: 1497-1506, 1997

3. O'Mahony D, Peikarz RL, Bandettini WP, Arai AE, Wilson WH and Bates SE: Cardiac involvement with lymphoma: A review of the literature. Clin Lymphoma Myeloma 8: 249-252, 2008.

4. Jonavicius K, Salcius K, Meskauskas R, Valeviciene N, Tarutis V and Sirvydis V. Primary cardiac lymphoma: two cases and a review of literature. J Cardiothorac Surg 2015; 10: 138.

5. Chin JY, Chung MH, Kim JJ, Lee JH, Kim JH, Maeng IH, Jung SY, Hwang HJ, Lee JB and Youn HJ. Extensive primary cardiac lymphoma diagnosed by percutaneous endomyocardial biopsy. J Cardiovasc Ultrasound 2009; 17: 141-144.

6. Nonami A, Takenaka K, Kamezaki K, Miyamoto T, Harada N, Nagafuji K, Teshima $T$ and Harada M. Successful treatment of primary cardiac lymphoma by rituximab-CHOP and high-dose chemotherapy with autologous peripheral blood stem cell transplantation. Int $\mathrm{J}$ Hematol 2007; 85: 264-266.

7. Gyoten T, Doi T, Nagura S, Yamashita A, Fukahara K, Kotoh K and Yoshimura N. Primary cardiac malignant lymphoma: survival for 13 years after surgical resection and adjuvant chemotherapy. Ann Thorac Surg 2015; 99: 1060-1062. 